\title{
100 years of insulin: victories, hopes, and existing challenges
}

\author{
Krystyna Pierzchała-Koziec ${ }^{1}$, Colin G. Scanes ${ }^{2,3}$ \\ ${ }^{1}$ Department of Animal Physiology and Endocrinology, University of Agriculture in Krakow, Krakow, Poland \\ ${ }^{2}$ Center of Excellence in Poultry Science, University of Arkansas, Fayetteville, United States \\ ${ }^{3}$ Department of Biological Science, University of Wisconsin, Milwaukee, United States
}

\begin{abstract}
$\mathrm{T}_{\mathrm{s}, \mathrm{s}}$ his year marks the $100^{\text {th }}$ anniversary of the discovery of insulin and its subsequent development as a therapy for diabetes. There are many publications with the same conclusion as that of Frederick Banting in his Nobel lecture: Insulin is not a cure for diabetes; it is a treatment. The history of the discovery of insulin is a story that had begun long before the identification of this hormone. Two findings were crucial because they provided a model for the study of diabetes: first, recognition of pancreas islets by Paul Langerhans in 1869 [1], and second, the observation that pancreatomy in dogs caused glycosuria [2].

The relative roles played by the major Canadian researchers in a laboratory in Toronto in the discovery of insulin are still controversial. The leader of the laboratory was John MacLeod. In 1921, Frederick Banting and Charles Best prepared an extract from the pancreas and administered it to a diabetic patient. This resulted in decreasing hyperglycaemia.

Frederick Banting and John MacLeod received the Nobel prize in 1923 for the discovery of insulin. They and their collaborators established that an extract from the pancreas overcame diabetes [3,4]. An extract of pig and cow pancreas was shortly employed effectively to treat patients with diabetes [5]. Without this, many diabetics would have died. While Banting and MacLeod received the Nobel prize, this would have been a bitter sweet situation for their collaborators, Charles Best and James Collip, but for Banting and MacLeod sharing the prize. However, other collaborators did not share in the award or largess. Moreover, history records the discovery as the work of Banting and Best with the contribution of MacLeod and Collip dismissed, arguably unfairly [1]. Besides, earlier research, which was essential to the discovery, did not get the same level of credit [5].
\end{abstract}

\section{Other landmarks in the history of insulin}

Insulin has an illustrative history that was recognized with Nobel prizes:

— chemical structure of insulin (amino-acid residue sequence) by Frederick Sanger (1958);

— three-dimensional structures of insulin by Dorothy Hodgkin (1964);

— development of radioimmunoassay initially for insulin by Rosalyn Yalow (1977) [5].

The development of the technique of radioimmunoassay by Yalow and Berson (1960) was a major advance, allowing determination of hormones in the plasma of people, domesticated and laboratory animals, and wild animals. Moreover, according to Kahn and Roth [6], Berson and Yalow clearly demonstrated that type 1 diabetes was an insulin-deficient state, whereas patients with type 2 diabetes had substantial amounts of insulin in the blood and could be classified as insulin resistant.

\section{The insulin superfamily}

The insulin superfamily consists of the following peptides that can be assigned to the following groups:

— insulin and insulin-like peptides that act via an insulin (or insulin like) receptor tyrosine kinase;

- insulin-like growth factors (IGF) acting via an IGF receptor tyrosine kinase;

- relaxin [relaxin (RLN)-1, 2, 3 and insulin-like peptides (INSL) 3, 4, 5 and 6]; acting via a G-protein-coupled relaxin family peptide receptor (RXFP);

— gonadulins in arthropods [7]. 


\section{The history of insulin therapy}

Insulin was the first pharmaceutical therapy using recombinant DNA technology. Animal insulins extracted from the pancreas tissue had been used for therapy for more than 50 years (1922-1974) until semisynthetic human insulin was created by modification of animal insulins followed by the application of recombinant DNA technology to the biosynthesis of human insulin on an industrial scale. In 1982, Humulin, the first human insulin for diabetes treatment produced in Escherichia coli by recombinant DNA technology, was approved. During the next decade recombinant human insulins, produced by different processes of biosynthesis in bacteria and yeast, were approved in the USA and Europe [8].

\section{Understandings about routes of administration}

Injection by the subcutaneous route is associated with a longer action profile of insulin. The major steps in the development of insulin to be administered by this route include the following: 1. purification of insulin, 2 . formulation to reduce antibody formation together with allergic and injection site reactions, 3 . mechanisms to delay insulin absorption allowing basal insulin coverage, and 4. changes to accelerate absorption of insulin for prandial therapy. Also, it must be remembered that insulin treatment is associated with a high risk of hypoglycaemia [9]. In order to avoid the many problems, more effective approaches for insulin delivery were developed; these included the following: 1. the first pancreas transplant in a human, performed in 1967; 2. U100 insulin introduced for better accuracy in administration in 1972; and 3. insulin pen delivery devices introduced together with short- (1996) and long- (2001) acting insulin analogues [8].

\section{Therapeutic consequences of insulin receptor}

The insulin receptor is a member of the ligand-activated receptor and tyrosine kinase family of transmembrane signalling proteins that are important regulators of cell differentiation, growth, and metabolism. The insulin receptor has several unique physiological and biochemical properties that allow it to play the main physiological role in the regulation of metabolic processes. Since the 1980s the understanding of intra-cellular signalling has advanced, and most of the pathways are now well defined. However, this significant understanding has not affected or dealt with problems of insulin therapy, such as insulin resistance. Nevertheless, while the mechanisms are not clear, the understandings around self-association to form dimers and hexamers, and where the receptor binding domain might lie, have led to the invention/production of long-acting insulin analogues and their rapid acting forms [8,9].

\section{Perspectives and challenges}

The prevalence of diabetes is increasing at an alarming rate in all regions of the world. This is due, at least in part, to unhealthy lifestyles, lack of physical activity, and a greater proportion of people who are overweight and obese.

\section{Diabetes in 2021}

Diabetes mellitus (DM) is a series of diseases resulting in hyperglycaemia. There are two major types of DM:

- type $1 \mathrm{DM}$ (T1DM) results from the autoimmune destruction of beta cells, leading to insulin insufficiency and the need for exogenous insulin. Type $1 \mathrm{DM}$ develops in young people;

- type 2 DM (T2DM) is a progressive metabolic disease caused by insulin resistance. This typically develops in middle-aged people.

According to the world Health Organization (WHO), 422 million people in the world have DM, with 1.6 million deaths per year. In industrialized countries, about $10 \%$ of the population have diagnosed DM with a further $3 \%$ undiagnosed [10].

The number of adults with diabetes in Poland was reported as 2.9 million (1.3 million men and 1.6 million women in 2018), constituting $9.5 \%$ of the adult population. Still, the number of undiagnosed individuals is unknown and is probably growing.

\section{Diabetes, mortality and morbidity}

UK studies have shown increased mortality in type 1 and type 2 DM; this being due at least in part to cardiovascular disease, ischaemic heart disease, cerebrovascular disease, and respiratory disease [11]. In an American study, mortality was markedly higher in diabetics [12]. Diabetes was associated with death from ischaemic heart disease in a study from Norway [13]. Similarly, a shorter life expectancy was observed in people with type 1 diabetes compared to non-diabetics in a Bulgarian study [14]. In addition, diabetics have a 30-fold higher rate of amputations than non-diabetics [15]. 
Other factors influence life expectancy in diabetics. For instance, smoking, poor renal functioning, and high body mass index (BMI) were associated with reduced life expectancy in type 2 DM. Moreover, mortality in individuals with type $1 \mathrm{DM}$ is affected by BMI and diabetic nephropathy $[16,17]$. Obesity leads to a dysregulation of miRNA expression in adipose tissue, and changes in miRNA expression relate to changes in gene expression, which are in turn related to the development of insulin resistance [18]. In Poland, the main risk factors connected with diabetes are overweight, obesity, and physical inactivity (WHO, 2016), with the proportional mortality (diabetes vs. total deaths) in 2019 being $2 \%$ [10].

The main challenge today is to slow or reverse the increase in the prevalence of diabetes. This requires improved education and early hyperglycaemia diagnosis. Moreover, this is still a critical need for research.

In perspective the problems of developing insulin administration by nasal and oral routes, creating single-chain insulins with high thermal stability, insulin pumps, and closed-loop insulin administration will hopefully be solved. This will result in progressive improvements in the safety and efficacy of insulin therapy.

\section{Conclusions}

In the words of the great Polish/British author, Joseph Conrad/Józef Teodor Konrad Korzeniowski, Principles? Principles won't do. They wanted facts. Research on insulin continues to need facts, principles, but also solutions that address the needs of diabetics.

It is anticipated that biotechnology will facilitate the development of additional approaches of regenerative medicine, gene therapy, and smart insulins. This will potentially overcome the physiological barriers. However, the question arises: how long will it take before hepato-preferential, oral, and glucose-responsive insulins become accessible for patients?

\section{Conflict of interest}

None declared.

\section{Funding sources}

This research was financed by the Ministry of Science and Higher Education of the Republic of Poland Sub. 020002-D-015.

\section{References}

1. Fralick M, Zinman B. The discovery of insulin in Toronto: beginning a 100 year journey of research and clinical achievement. Diabetologia. 2021; 64(5): 947-953, doi: 10.1007/s00125-020-05371-6, indexed in Pubmed: 33492422.

2. Mering J, Minkowski O. Diabetes mellitus nach Pankreasextirpation. Centralblatt für Klinische Medicin, Leipzig. 1889; 10(23): 393-394.

3. Banting FG, Best CH, Collip JB, et al. Preliminary studies of the physiological of insulin. Trans R Soc Can. 1922a; 16: 18-21.

4. Banting FG, Best CH, Collip JB, et al. The effect of pancreatic extract (insulin) on normal rabbits. Am J Physiol. 1922b; 62(1): 162-176, doi: 10.1152/ajplegacy.1922.62.1.162.

5. Vecchio I, Tornali C, Bragazzi NL, et al. The Discovery of Insulin: An Important Milestone in the History of Medicine. Front Endocrinol (Lausanne). 2018; 9: 613, doi: 10.3389/fendo.2018.00613, indexed in Pubmed: 30405529.

6. Kahn CR, Roth J. Berson, Yalow, and the JCI: the agony and the ecstasy. J Clin Invest. 2004; 114(8): 1051-1054, doi: 10.1172/JCI23316, indexed in Pubmed: 15489951.

7. Veenstra JA. Arthropod IGF, relaxin and gonadulin, putative orthologs of insulin-like peptides 6,7 and 8, likely originated from an ancient gene triplication. PeerJ. 2020; 8: e9534, doi: 10.7717/peerj.9534, indexed in Pubmed: 32728497.

8. Home P. The evolution of insulin therapy. Diabetes Res Clin Pract. 2021; 175(1-9): 108816, doi: 10.1016/j.diabres.2021.108816, indexed in Pubmed: 33862058.

9. Rokicka D, Marek B, Kajdaniuk D, et al. Hypoglycaemia in endocrine, diabetic, and internal diseases [Hipoglikemia w schorzeniach endokrynologicznych, diabetologicznych i internistycznych]. Endokrynol Pol. 2019; 70(3): 277-297, doi: 10.5603/ep.a2019.0020, indexed in Pubmed: 31290559.

10. WHO, 2021. Diabetes. https://www.who.int/health-topics/diabetes\#tab=tab_1.

11. Leal J, Gray AM, Clarke PM. Development of life-expectancy tables for people with type 2 diabetes. Eur Heart J. 2009; 30(7): 834-839, doi: 10.1093/eurheartj/ehn567, indexed in Pubmed: 19109355.

12. Gu K, Cowie CC, Harris MI. Mortality in adults with and without diabetes in a national cohort of the U.S. population, 1971-1993. Diabetes Care. 1998; 21(7): 1138-1145, doi: 10.2337/diacare.21.7.1138, indexed in Pubmed: 9653609.

13. Dale AC, Nilsen TI, Vatten L, et al. Diabetes mellitus and risk of fatal ischaemic heart disease by gender: 18 years follow-up of 74,914 individuals in the HUNT 1 Study. Eur Heart J. 2007; 28(23): 2924-2929, doi: 10.1093/eurheartj/ehm447, indexed in Pubmed: 17947212.

14. Tachkov K, Mitov K, Koleva Y, et al. Life expectancy and survival analysis of patients with diabetes compared to the non diabetic population in Bulgaria. PLoS One. 2020; 15(5): e0232815, doi: 10.1371/journal.pone.0232815, indexed in Pubmed: 32392235.

15. Molina CS, Faulk JB. Lower extremity amputation. StatPearls Publishing, Treasure Island 2021.

16. Dahlström EH, Sandholm N, Forsblom CM, et al. Body Mass Index and Mortality in Individuals With Type 1 Diabetes. J Clin Endocrinol Metab. 2019; 104(11): 5195-5204, doi: 10.1210/jc.2019-00042, indexed in Pubmed: 31034018.

17. Kułaczkowska ZM, Wróbel M, Rokicka D, et al. Metformin in patients with type 2 diabetes mellitus and heart failure: a review. Endokrynol Pol. 2021; 72(2): 163-170, doi: 10.5603/EP.a2021.0033, indexed in Pubmed: 33970481.

18. Estrella Ibarra P, García-Solís P, Solís-Sáinz JC, et al. Expression of miRNA in obesity and insulin resistance: a review. Endokrynol Pol. 2021; 72(1): 73-80, doi: 10.5603/EP.a2021.0002, indexed in Pubmed: 33749820. 